01,05

\title{
Особенности фазового состава и структуры доэвтектоидной стали, проявляющиеся в поведении намагниченности вблизи магнитного насыщения
}

\author{
(C) С.В. Комогорцев, С.В. Семенов, С.Н. Варнаков, Д.А. Балаев \\ Институт фризики им. Л.В. Киренского ФИЦ КНЦ СО РАН, \\ Красноярск, Россия \\ ฯ E-mail: dabalaev@iph.krasn.ru
}

Поступила в Редакцию 28 августа 2021 г.

В окончательной редакции 28 августа 2021 г.

Принята к публикации 3 сентября 2021 г.

\begin{abstract}
Исследование температурной эволюции кривых намагничивания вблизи магнитного насыщения позволяет извлекать новую информацию об особенностях фазового состава и структуры доэвтектоидной стали. Показано, что основной вклад в величину и температурное поведение плотности энергии локальной магнитной анизотропии доэвтектоидной стали обусловлен пластинчатым строением перлита. Особенность температурного поведения энергии локальной магнитной анизотропии наряду с поведением парапроцесса указывает на формирование Мn-замещенного цементита в исследованном образце стали. Наблюдение кроссовера степенных закономерностей в приближении намагниченности к насыщению указывает на формирование двумерных нанонеоднородностей локальной оси легкого намагничивания в пластинах альфажелеза, входящих в состав перлита.
\end{abstract}

Ключевые слова: намагниченность, сталь, цементит, железо, приближение к намагниченности к насыщению, перлит.

DOI: 10.21883/FTT.2022.01.51827.192

\section{1. Введение}

Сталь является одним из лидеров среди материалов, востребованных на практике, поэтому исследование ее структуры и свойств тесно вплетено в историю человечества, науки и техники. Следуя основной парадигме науки о материалах, подробнейшим образом исследованы и продолжают исследоваться структура стали на различных масштабах (от масштаба межатомных расстояний до десятков микрон) и ее связь со свойствами (задача адекватного цитирования здесь выглядит просто невыполнимой, поэтому сошлемся на две из последних монографий, затрагивающих историю и текущее состояние вопроса $[1,2])$. Новая информация, как и в любой „горячей“ области науки о материалах здесь появляется в связи, с прогрессом измерительной техники, позволяющей применить для анализа структуры либо свойств недоступные ранее, по разным причинам, подходы и методы. Примером, может служить прогресс в применении микроскопических методов, позволяющих находить новое в структуре стали на наномасштабе $[3,4]$.

Магнитоструктурные методы занимают важное место в исследованиях стали и здесь интересные возможности появляются в связи с широким распространением новой высокоточной магнитометрической техники, позволяющей оперативно проводить исследования в высоких полях и широком диапазоне температур. Хорошо известный метод магнитофазового анализа [5] в связи с этим может давать новые возможности при получении инфор- мации не только о фазовом составе, но и об особенностях микро и наноструктуры [6,7]. Согласно традиционному магнитофазовому анализу, по температурной зависимости намагниченности $M(T)$, можно, как идентифицировать фазу по величине температуры Кюри (например, для классического цементита $\mathrm{Fe}_{3} \mathrm{C} T_{\mathrm{C}}=480 \mathrm{~K}$ ), так и оценить ее количество, представляя $M(T)$ как сумму парциальных вкладов в намагниченность от отдельных фаз [5]. Представляет интерес возможность извлекать из магнитных измерений информацию о такой неизменной структурной составляющей стали как перлит. Перлит является продуктом эвтектоидного распада аустенита при сравнительно медленном охлаждении железоуглеродистых сплавов ниже $727^{\circ} \mathrm{C}[1,2]$ и представляет собой смесь двух фаз: ОЦК-Fе, содержащего от 0.006 до $0.025 \%$ углерода и цементита. Пластинчатый перлит, где обе фазы чередуются и имеют форму пластинок, является основным видом перлита в составе доэвтектоидных сталей. В нашей работе мы продемонстрируем, как пластинчатая структура перлита проявляется в результатах магнитометрических измерений и, таким образом, как информация, извлекаемая из таких измерений может быть использована для исследования этой важной структурной составляющей доэвтектоидной стали. Кроме того, в настоящей работе мы продемонстрируем дополнительные возможности исследования доэвтектоидной стали с помощью использования современной магнитометрической техники и развития подходов к обработке данных вблизи магнитного насыщения. 
Отметим также, что развитие методов анализа магнитных свойств конструкционных сталей связано еще с одной задачей - необходимостью понимания процессов, происходящих в сталях, работающих в агрессивных средах при высоких температурах, например, в качестве элементов электролитических ванн в производстве алюминия. В этом случае поведение намагниченности материала электролитической ванны важно для контроля и симуляции магнитогидродинамических параметров работы электролизера $[8,9]$.

\section{2. Эксперимент}

Исследовался образец конструкционной стали Ст-3 (ГОСТ 380-2005) [10]. Образцы для измерений изготавливались в форме шара массой около $80 \mathrm{mg}$ (при пробоподготовке температура образца не поднималась выше $\left.120^{\circ} \mathrm{C}\right)$.

Магнитные измерения (кривые намагничивания $M(H)$ и температурные зависимости намагниченности $M(T)$ ) проводились на вибрационном магнетометре LakeShore VSM 8604. Зависимости $M(H)$ и $M(T)$ измерялись при повышении температуры. Поскольку при температурах выше $1000 \mathrm{~K}$ происходили необратимые превращения, образец отогревался только один раз, после чего измерялся новый образец исходной стали. Перед каждым измерением $M(H)$ проводилось размагничивание образца. Зависимости $M(H)$ (величина магнитного поля) корректировались с учетом фактора формы образца [11].

\section{3. Результаты и обсуждение}

\section{1. Температурное поведение намагниченности в поле $10 \mathrm{kOe}$}

Температурный ход намагниченности, измеренной в поле $H=10 \mathrm{kOe}$ (рис. 1,a), отражает как особенности магнитной подсистемы (температура Кюри ОЦК-железа $T_{\mathrm{C}} \approx 1043 \mathrm{~K}$ ), так и структурные превращения в стали при высоких температурах (вблизи температуры эвтектоидного превращения стали при $\left.T_{e} \approx 1000 \mathrm{~K}[1,2]\right)$. Указанные температуры $T_{\mathrm{C}}$ и $T_{e}$ отчетливо проявляются на производной $d M / d T$, приведенной на рис. $1, b$.

Доэвтектоидная сталь с содержанием углерода $0.14 \div 0.22$ wt. $\%$ содержит от 2.2 до 3.4 wt.\% цементита. Переход цементита в парамагнитное состояние выше $480 \mathrm{~K}$ (температура Кюри классического цементита) $[5,12]$ должен приводить к ступеньке на температурном ходе намагниченности вблизи этой температуры, однако, в пределах доступной точности измерений такая ступенька достоверно не наблюдается. Учитывая, что цементит характеризуется высокой константой магнитокристаллической анизотропии, а также то, что микроструктура перлита способна порождать высокую магнитостатическую локальную магнитную анизотропию, можно предположить, что поле $10 \mathrm{kOe}$ недостаточно
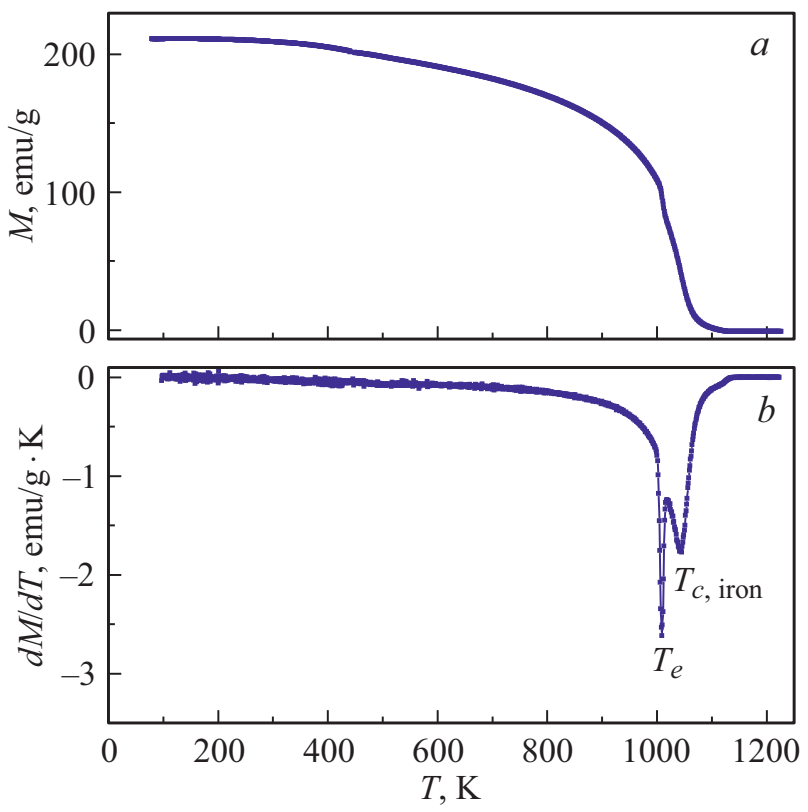

Рис. 1. Температурная зависимость $M(T)-(a)$ в поле $H=10 \mathrm{kOe}$ и ее производная $d M / d T-(b)$ исследованного образца стали.

для полного технического насыщения. Далее, для разрешения этих сомнений, мы анализируем кривые приближения намагниченности к насыщению в различных температурах.

\section{2. Приближение намагниченности к насыщению}

На рис. 2 представлены кривые намагничивания $M(H)$ в диапазоне температур $80 \div 1200 \mathrm{~K}$ в координатах $(H, T, M)$. Важно заметить, что в достаточно больших

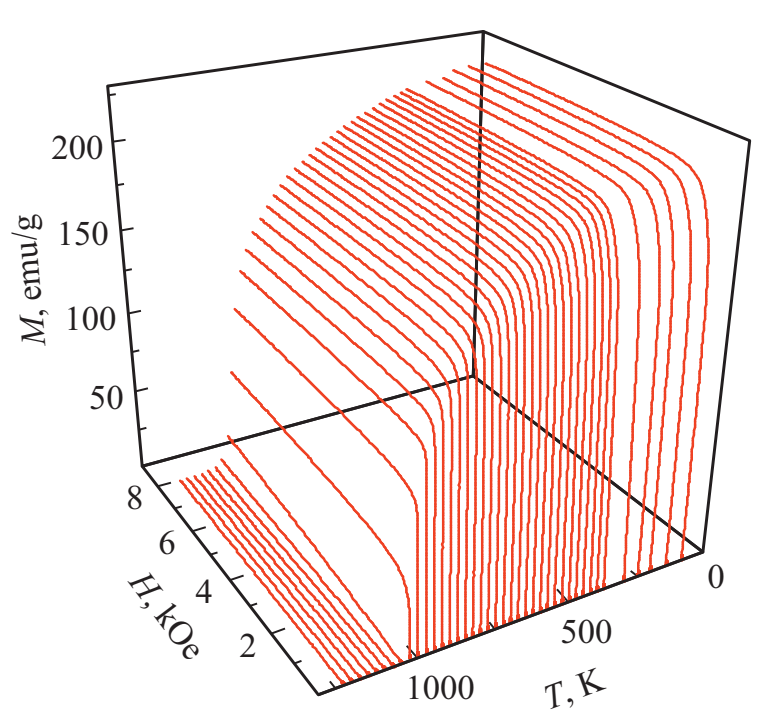

Рис. 2. Кривые намагничивания стали, измеренные при различных температурах. 


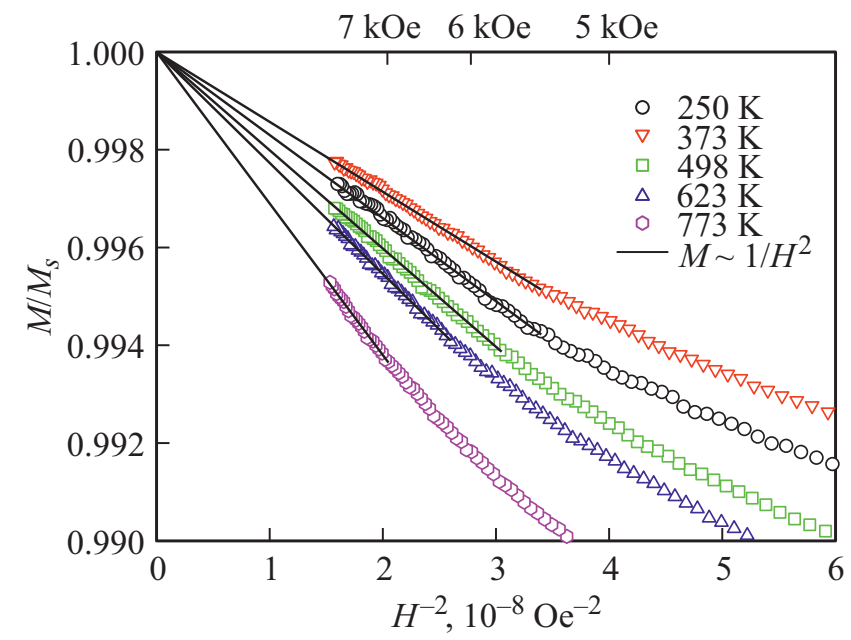

Рис. 3. Предварительный анализ приближения намагниченности к насыщению в координатах $\left(H^{-2}, M\right)$ для оценки достаточности уравнения (1) при описании эксперимента.

полях зависимости $M(H)$ имеют тенденцию к выходу на насыщение (постоянное значение намагниченности). При этом наблюдается зависимость

$$
M(H)=M_{s} \cdot\left(1-A \cdot H^{-2}\right),
$$

известная как закон приближения к насыщению Н.С. Акулова (в выражении (1) $A$ - константа). Это проиллюстрировано на рис. 3, на котором выборочные репрезентативные зависимости $M(H)$ приведены в координатах $\left(H^{-2}, M\right)$. Соответствие данных прямым линиям на рис. 3 указывает на выполнение зависимости (1). Из выборочных данных рис. 3 видно, что при повышении температуры полевой диапазон выполнения зависимости (1) уменьшается с повышением температуры. Закон Акулова описывает приближение к насыщению ферромагнетика со случайно ориентированной осью легкого намагничивания локальной магнитной анизотропии [13-15] и отражает конкуренцию локальной магнитной анизотропии, связанной с различными неоднородностями структуры и внешнего поля.

Исходя из принципа „бритвы Оккама“ использование уравнения (1) может показаться достаточным для описания кривых намагничивания в высоких полях. Однако, наши попытки такого описания показывают, что диапазон полей, где выполняется такая зависимость, укорачивается при повышении температуры, а коэффициент $A$ увеличивается. Это заставляет усомниться в правильности и достаточности использования только уравнения (1). В действительности, для приближения намагниченности к насыщению в ферромагнитных материалах, в частности, в железе, необходимо учитывать еще одно слагаемое, связанное с магнитной восприимчивостью, так называемый парапроцесс $\chi \cdot H$, индуцируемый в магнитной подсистеме ферромагнетика в результате конкуренции высоких полей и тепловых флуктуаций [16,17]. В этом случае приближение к насыщению следует описывать более сложным уравнением

$$
M(H)=M_{s} \cdot\left(1-A \cdot H^{-2}\right)+\chi \cdot H .
$$

На рис. 4 показано, что учет слагаемого $\chi \cdot H$ увеличивает область полей, где кривая намагничивания спрямляется в координатах $\left(H^{-2}, M\right)$. Кроме того, такое описание приводит к физически разумному снижению коэффициента $A$ с ростом температуры (рис. 7). Промежуточный вывод, следующий из такой работы с данными: приближение намагниченности к насыщению исследуемой стали в диапазоне от 5 до $8 \mathrm{kOe}$ хорошо описывается выражением (2). На рис. 2, где представлены все кривые намагничивания, можно наблюдать возрастание роли второго слагаемого при переходе через температуру Кюри ОЦК-железа, что находит количественное подтверждение в результате предварительного описания данных уравнением (2).

Учитывая вышесказанное, был проведен компьютерный фитинг измеренной кривой $M(H)$ зависимостью (2) в диапазоне полей от 5 до $8 \mathrm{kOe}$. Этот диапазон также соответствует условию: величина первого нелинейного слагаемого в уравнении (2) не превышает 1\% от полного сигнала. Контроль малости слагаемых в уравнении (2) связан с тем, что теоретические выражения, в дальнейшем используемые для анализа данных, получены в предположении малых отклонений намагниченности от полного насыщения. Качество подгонки до температуры 975 K весьма удовлетворительно - отклонение подгоночных кривых от экспериментальных данных однородны и согласуются с величинами случайной погрешности измерений намагниченности (рис. 5). Выше $1043 \mathrm{~K}$, параметр $A$ был настолько мал, что при подгонке уравнением (2) было использовано только второе слагаемое.

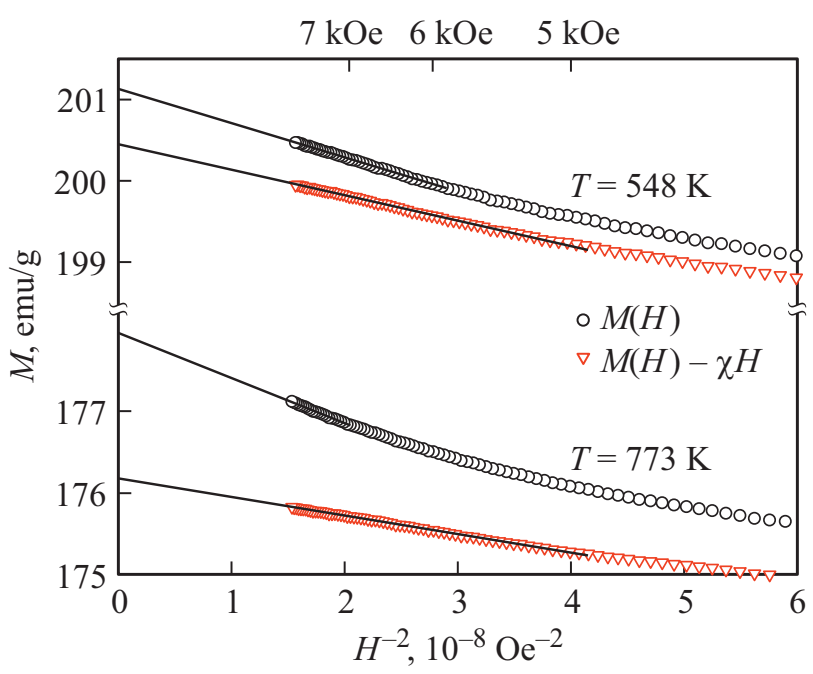

Рис. 4. Эффект учета вклада парапроцесса для описания приближения намагниченности к насыщению. 

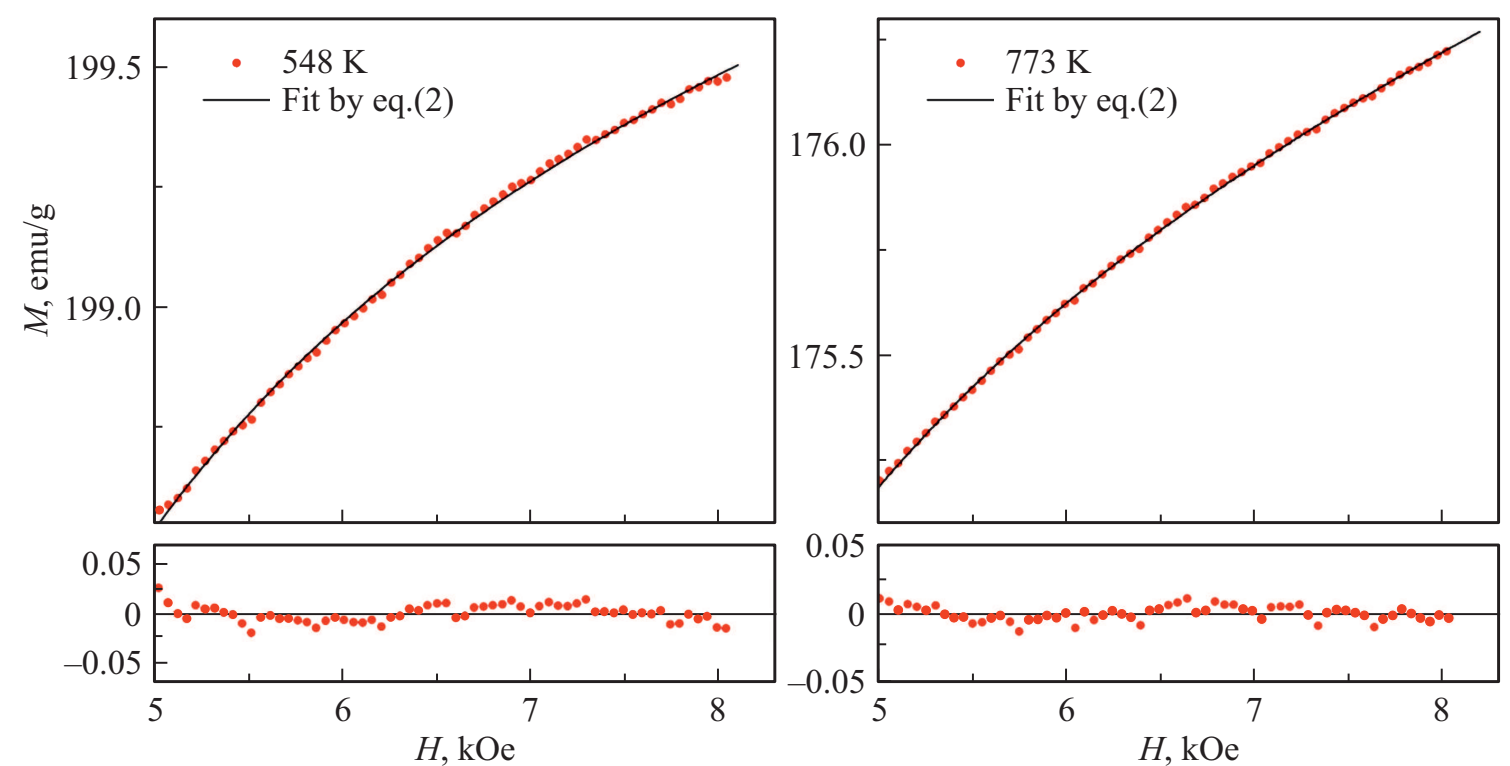

Рис. 5. Фитинг измеренной кривой намагничивания (символы) уравнением (2). На нижних вставках - отклонение измеренной намагниченности от предсказаний уравнения (2).

\section{3. Температурная эволюция параметров, характеризующих приближение намагниченности к насыщению и их связь с микроструктурными особенностями стали}

Величины подгоночных параметров $\left(M_{s}, A, \chi\right)$, полученных в результате фитинга приближения намагниченности к насыщению от 5 до $8 \mathrm{kOe}$, позволяют проследить изменения в магнитной подсистеме стали с изменением температуры. Величина $M_{s}$ представляет собой результат экстраполяции процесса технического насыщения к бесконечным полям и может рассматриваться как величина спонтанной намагниченности при данной температуре. На рис. 6 мы сравниваем данные по $M_{s}$ с предсказаниями формулы

$$
M_{s}=M_{s 0} \cdot\left[1-s \cdot\left(T / T_{c}\right)^{3 / 2}-(1-s) \cdot\left(T / T_{c}\right)^{p}\right]^{1 / 3},
$$

предложенной недавно в работе [18] в качестве универсальной для широкого класса ферромагнитных материалов. В данной формуле предполагается, что низкотемпературное поведение намагниченности следует т. н. закону Блоха $T^{3 / 2}$ применимость которого для металлов и металлических сплавов обсуждалась ранее и продолжает обсуждаться в последнее время [7,19-23]. Точкой согласия в этих дискуссиях, однако является то, что это поведение должно описываться степенным законом типа $M \propto T^{n}$, спор касается лишь величины показателя степени ( $n=3 / 2$ либо 2). Поскольку минимальная температура, при которой мы измеряли кривую намагничивания, составляла $85 \mathrm{~K}$ можно считать, что „спорный“ низкотемпературный участок находится вне диапазона полученных данных. В целом, как видно из рис. 6 , удается получить замечательное согласие данных

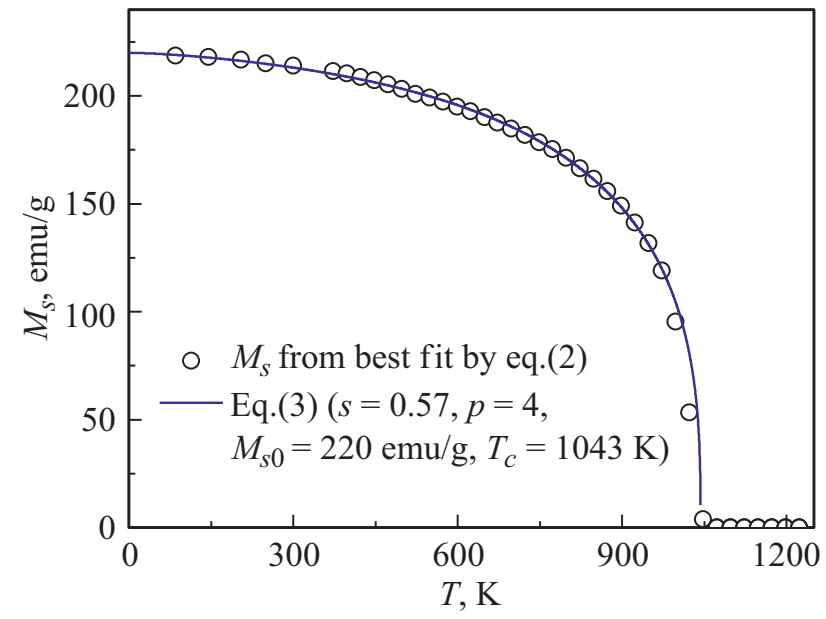

Рис. 6. Температурное поведение намагниченности насыщения стали и его описание уравнением (3).

и предсказаний формулы (3) при выборе подгоночных параметров, приведенных на легенде к рис. 6. Основная весовая доля материала $(\approx 97 \%)$ представляет собой ОЦК-железо. Это, по-видимому, отражается в том, что величина параметра $p=4$, совпадает с таковой для чистого $\mathrm{Fe}$, при этом значительно отличаясь от величин для других ферромагнетиков [18]. Параметр $s=0.57$ несколько отклоняется от параметра для чистого железа $(s=0.35)$, приведенного в [18]. Некоторые отклонения выше $975 \mathrm{~K}$, вероятно, являются следствием частично осуществившегося эвтектоидного превращения в стали (см. п. 3.1 и рис. 1).

Температурное поведение высокополевой магнитной восприимчивости (рис. 7) помимо особенности, свя- 


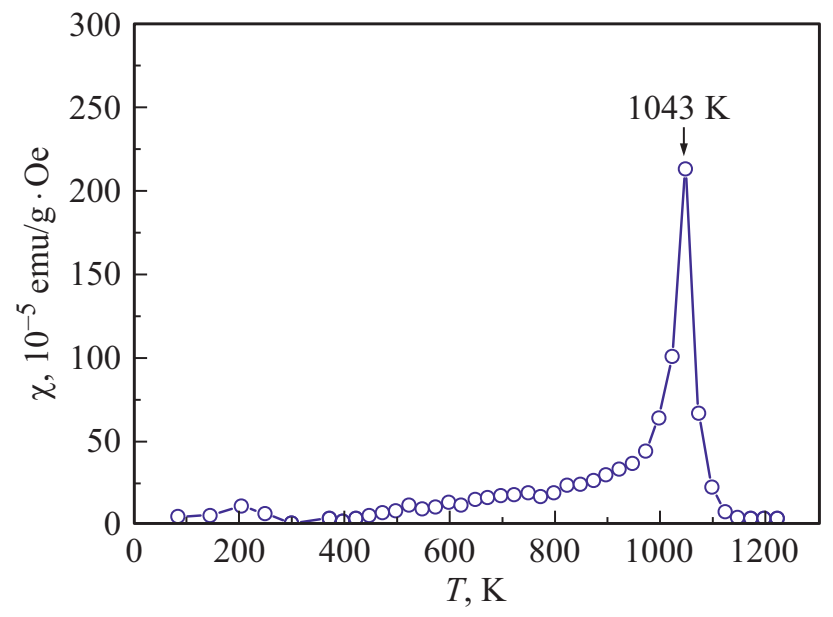

Рис. 7. Температурное поведение высокополевой магнитной восприимчивости стали.

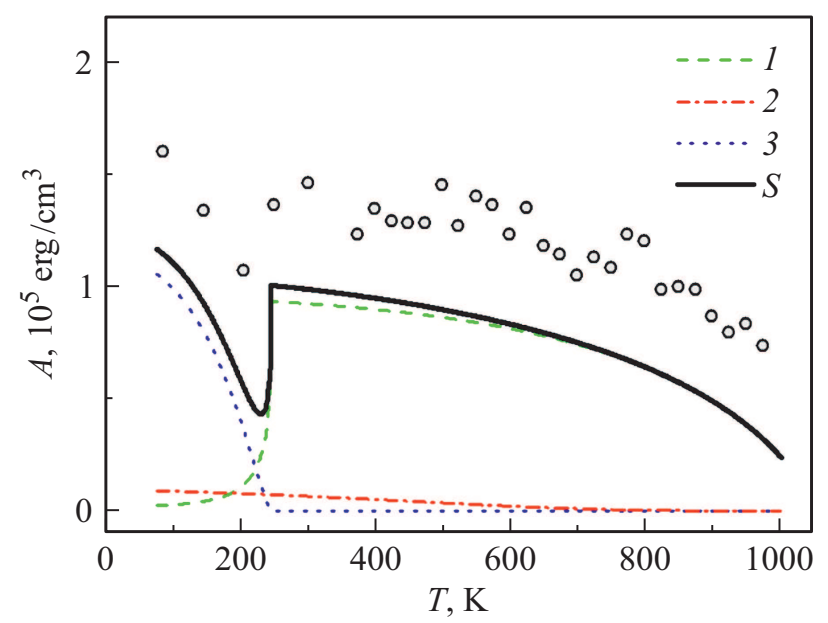

Рис. 8. Температурное поведение коэффициента $A$, полученное фитингом данных уравнением (2) (символы) и оцененное по уравнению (4) (толстая черная линия - суммарная оценка, тонкие цветные линии - вклады различных слагаемых в уравнении (4): 1 - магнитостатический вклад перлита; 2 - вклад магнитокристаллической анизотропии ОЦК-Fе; 3 - вклад магнитокристаллической анизотропии цементита).

занной с температурой Кюри ОЦК-Fе обнаруживает небольшой пик между 205 и $250 \mathrm{~K}$. Температура Кюри $\mathrm{Fe}_{3} \mathrm{C}$, однако, гораздо выше (около $480 \mathrm{~K}$ ) [24]. Ниже мы приведем аргументы, что наблюдаемый пик отражает температуру Кюри Mn-замещенного цементита в исследуемом образце стали.

Коэффициент $A$ в выражении (2) является суммарным результатом различных вкладов, приводящих к неоднородности намагниченности в конечном поле, и может рассматриваться как своеобразная мера плотности энергии локальной магнитной анизотропии. Температурное поведение коэффициента $A$ показано на рис. 8. Если, оценить величину $A$ только в виде вклада от магнитокристаллической анизотропии альфа-железа как $A=\frac{2}{105} H_{a \text {, Fе }}^{2}$ (красная штрихпунктирная линия на рис. 8), оказывается, что измеренные величины $A$ более чем на порядок превосходят эту оценку (для оценки использовали известные данные для ОЦК-Fе [17,25]). Таким образом, в данном случае нельзя, считая, что на альфа-железо приходится основная доля материала (97wt.\%), пренебрегать прочими вкладами, включая вклад цементита. Далее проанализируем зависимость $A(T)$ как сумму следующих вкладов $[13,26-30]$, представляющихся наиболее важными на следующем этапе уточнения нашего анализа поведения $A(T)$ :

$$
\begin{aligned}
A= & \frac{2}{105} H_{a, \mathrm{Fe}}^{2}(1-x)+\frac{1}{15} H_{a, \mathrm{Fe}_{3} \mathrm{C}}^{2} \cdot x \\
& +\frac{1}{15}\left[4 \pi\left(M_{s, \mathrm{Fe}}-M_{s, \mathrm{Fe}_{3} \mathrm{C}}\right) \cdot p(1-p)\right]^{2} \cdot y,
\end{aligned}
$$

здесь $x$ - доля цементита в стали, $y$ - доля перлита в стали (для данного образца стали принято $y=0.26), p$ - доля цементита в составе перлита, $H_{a, \mathrm{Fe}}$, $H_{a, \mathrm{Fe}_{3} \mathrm{C}}-$ поля магнитокристаллической анизотропии альфа-железа и цементита, $M_{s, \mathrm{Fe}}, M_{s, \mathrm{Fe}_{3} \mathrm{C}}$ - намагниченности насыщения альфа-железа и цементита. Первое и второе слагаемое в выражении (4) дают вклады от магнитокристаллической анизотропии случайно ориентированных кристаллитов альфа-железа и цементита. Различие числовых коэффициентов при этих слагаемых отражает различие симметрии фаз альфа-железа (кубическая 2/105) и цементита (одноосная 1/15) [14]. Третье слагаемое учитывает магнитную анизотропию, вызванную неоднородностью строения перлита (показано схематично справа на рис. 9). Конструкция этого слагаемого отражает идею о том, что пластинчатое строение перлита (рис. 9) должно приводить к неоднородности магнитостатического поля, которое породит локальную магнитную анизотропию, наведенную магнитной анизотропией формы пластин, разностью их намагниченностей и их объемными долями.

Для количественного сравнения экспериментальной зависимости $A(T)$ с выражением (4) мы использовали доступные в литературе константы анизотропии ОЦК-Fе [17,25] и цементита [31,32], а также закон Акулова-Зинера, устанавливающий температурное по-
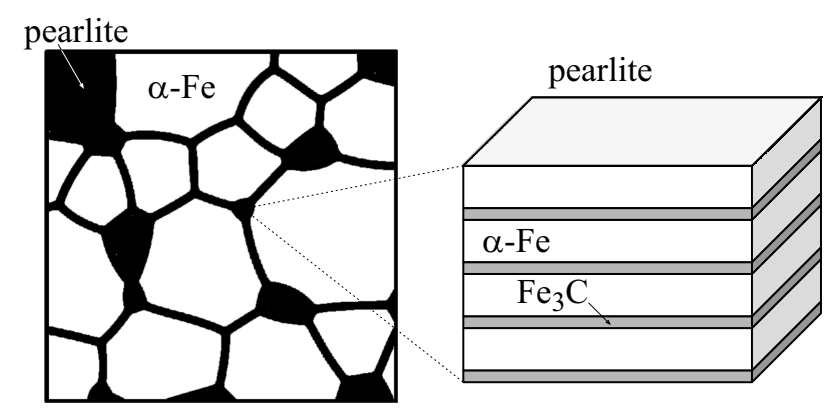

Рис. 9. Схематическое изображение микроструктуры доэвтектоидной стали - справа, строение перлита — слева. 
ведение констант анизотропии ферромагнетика и достаточно хорошо согласующийся с экспериментом [17,33]:

$$
K(T)=K(0) \cdot\left(M_{s}(T) / M_{s}(0)\right)^{m} .
$$

Поля анизотропии, входящие в уравнение (4), связаны с константами анизотропии как $H_{a}=2 \cdot K / M_{s}$. Показатель $m=10$ для ОЦК-Fе (кубическая анизотропия) и $m=3$ для цементита (одноосная анизотропия) [14]. Поведение $M_{s}(T)$ альфа-железа и цементита оценивали по уравнению (3), используя параметры $M_{s}(0)$ из $[17,25,31,32]$, для альфа-железа принимали $T_{\mathrm{C}}=1043 \mathrm{~K}$, для цементита выбрана $T_{\mathrm{C}}^{*}=240 \mathrm{~K}$ (обоснование такого выбора см. ниже), остальные параметры уравнения (3) приняты равными параметрам альфажелеза [18].

Из рис. 8 видно, что суммарное поведение вкладов (выражение (4)) описывает экспериментальные данные с точностью до некоторого постоянного вклада. Также, из рис. 7 видно, что в температурах, превышающих температурный переход цементита в парамагнитное состояние, основной вклад в температурное поведение $A(T)$ дает магнитостатический вклад структуры перлита. Кроме того, переход через температуру Кюри цементита неизбежно приводит к скачкообразному изменению вклада, связанного с магнитостатической анизотропией перлита, из-за резкого изменения взаимодействия между пластинами ОЦК-железа в структуре перлита. Особенность, связанная с $T_{\mathrm{C}}$ цементита, оказывается в диапазоне $200-250 \mathrm{~K}$, т.е. там же, где наблюдается пик магнитной восприимчивости, см. рис. 7. Причиной столь резкого снижения $T_{\mathrm{C}}$ цементита в сравнении с известной температурой Кюри $\mathrm{Fe}_{3} \mathrm{C}(480 \mathrm{~K})$ может являться частичное замещение атомов железа атомами марганца. В исследуемой доэвтектоидной стали (Ст-3) марганец является обязательным компонентом $(0.4 \div 0.65$ wt.\%). Отрицательная энтальпия формирования $\mathrm{Mn}_{3} \mathrm{C}(-20 \mathrm{~kJ} / \mathrm{mole})$ [34] по модулю значительно выше, чем максимальная энтальпия формирования ОЦК твердых растворов Fe-Mn (-1 kJ/mole) [35]. Это означает, что при формировании перлита в стали Ст-3, когда однородный аустенит должен распасться на цементит и ОЦК-Fе, атомам марганца (первоначально однородно распределенным в аустените), энергетически предпочтительнее войти в состав цементита. Учитывая содержание $\mathrm{Mn}$ в исследуемом образце, можно ожидать, что состав $\mathrm{Mn-замещенного} \mathrm{цементита}\left(\mathrm{Mn}_{x} \mathrm{Fe}_{1-x}\right)_{3} \mathrm{C}$ будет варьироваться в пределах $x=0.11 \div 0.185$. Согласно данным работ [36,37], где исследовались магнитные свойства Mn-замещенного цементита, температуры Кюри при таком уровне замещения должны наблюдаться в диапазоне от 140 до $280 \mathrm{~K}$. Поскольку наблюдаемая на рис. 7 и pис. 8 температура Кюри цементита $200 \div 250$ К попадает в этот диапазон, можно заключить, что в исследуемом образце стали формируется Мn-замещенный цементит. Этот вывод выглядит неожиданным, в виду того, что добавка марганца в сталях обыкновенного качества обосновывается необходимостью раскисления (удаления остаточного кислорода) [10,38]. Полученный нами результат означает, что иногда, как это, по-видимому, имеет место в нашем случае, добавка марганца, в следствии малого количества остаточного кислорода, вместо ожидаемого раскисления, встраивается в состав цементита, изменяя при этом его свойства (температура Кюри).

Различие на постоянную величину между данными $A(T)$, полученными из эксперимента, и выражения (4) (см. рис. 8), можно связать с неучтенными в уравнении (4) вкладами. В первую очередь это магнитоупругий вклад, связанный с наличием внутренних напряжений в стали [26,27], далее в перлите характеризующемся развитой межфазной поверхностью можно ожидать вклада в константу локальной магнитной анизотропии от т.н. поверхностной магнитной анизотропии $[39,40]$ и наконец константа магнитокристаллической анизотропии Мn-замещенного цементита может оказаться выше, чем константа анизотропии $\mathrm{Fe}_{3} \mathrm{C}$, использованная для оценки с помощью уравнения (4). Правильный учет этих вкладов требует дополнительных экспериментальных исследований. На данном этапе мы ограничиваемся констатацией хорошего качественного согласия данных и оценки на рис. 8 позволяющей сделать следующие выводы: 1) наблюдаемая особенность (минимум) вблизи $T_{\mathrm{C}}^{*} \sim 240 \mathrm{~K}$ на $A(T)$ отражает температуру Кюри Мn-замещенного цементита; 2) основной вклад в величину и температурное поведение $A(T)$ выше $T_{\mathrm{C}}^{*}$ связан с пластинчатым строением перлита. Эти находки также означают, что использованные нами подходы, являются полезным инструментом для анализа состояния перлита в доэвтектоидной стали.

\section{4. Кроссовер степенной закономерности приближения намагниченности к насыщению}

Для того, чтобы отследить степенные режимы в приближении намагниченности к насыщению, величина $\left(M_{s}-(M(H)-\chi \cdot H)\right) / M_{s}$ (т. н. дисперсия намагниченности [41-43]), согласно уравнению (2), дающая нелинейный вклад в приближение намагниченности к насыщению, представлена на рис. 10 в зависимости от внешнего поля в двойных логарифмических координатах. Отклонение от полного технического насыщения, для данных рис. 10, отложенное по оси ординат не превышает $2 \%$, т. о. основные положения теории приближения намагниченности к насыщению остаются в силе. Участок, описываемый нелинейным слагаемым из уравнения (2) для различных $M(H)$ здесь наблюдается, как прямая линия с тангенсом наклона, равным -2 . Также видно, что ниже $4 \mathrm{kOe}$ для различных температур (охватывающих практически весь исследованный диапазон температур) наблюдается степенное поведение (прямые линии с тангенсами наклона от -0.75 до -1 ).

Показатели степени в диапазоне $-0.75 \div-1$, согласно работам [41-44], соответствуют двумерным корреля- 


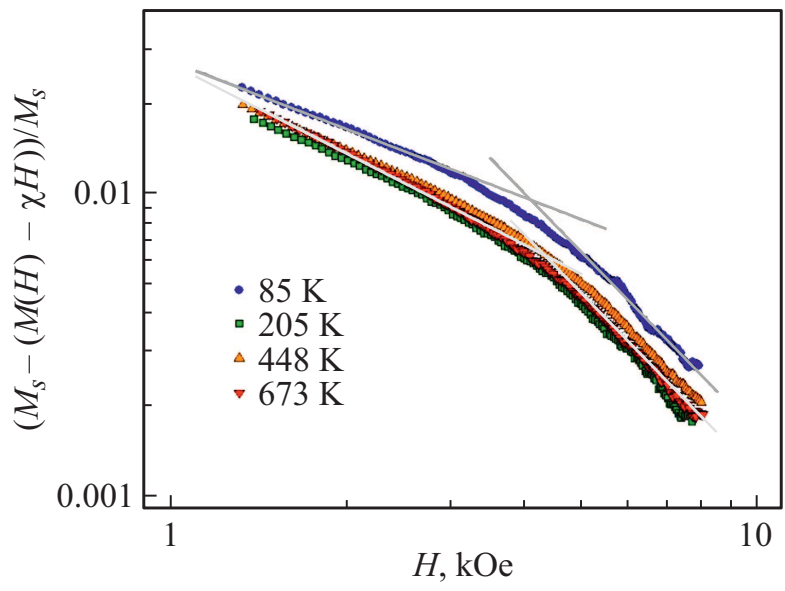

Рис. 10. Степенные закономерности, проявляющиеся в полевом поведении отклонения намагниченности от насыщения (прямолинейные участки).

циям намагниченности. Как показано в п. 3.3, основной вклад в отклонение намагниченности от насыщения возникает от структуры перлита. В этом случае естественно ожидать, что наблюдаемый двумерный характер корреляций намагниченности также будет связан с пластинчатым строением перлита, которое облегчает распространение корреляций в плоскости, но препятствует такому распространению поперек плоскости пластин перлита. Размер структурных неоднородностей - корреляционная длина локальной оси легкого намагничивания может быть оценен из величины поля $H_{R} \approx 4.5 \mathrm{kOe}$ смены степенных зависимостей, наблюдаемого на рис. 10 как $l_{c}=\sqrt{2 C /\left(M_{s} H_{R}\right)}[43]$, где $C=2.1 \cdot 10^{-6} \mathrm{erg} / \mathrm{cm}-$ константа обменного взаимодействия альфа-железа [20]. Оценка дает $l_{c} \approx 8 \mathrm{~nm}$. Столь малый размер означает, что железо в составе пластин перлита структурно неоднородно на наномасштабе. Согласно работам [45,46], в сочетании с наблюдаемыми проявлениями двумерного характера корреляций намагниченности, это также указывает на т.н. анизомерность структурных неоднородностей альфа-железа в составе пластин перлита. Термин анизомерные неоднородности подразумевает, что область однородной ориентации локальной оси легкого намагничивания локализована в двух измерениях на значительно более коротких масштабах, чем в третьем [44]. Для пластин альфа-железа в составе перлита, естественно предположить, что два таких измерения находятся в плоскости пластины, в то время как третье перпендикулярно ей (сделанная выше оценка $l_{c} \approx 8 \mathrm{~nm}$ по-видимому относится к размеру неоднородности в плоскости пластины).

\section{4. Заключение}

Исследование температурного и полевого поведения намагниченности образца доэвтектоидной стали Ст-3 вблизи магнитного насыщения с помощью современной магнитометрической техники, позволяет извлекать новую информацию как о поведении магнитной подсистемы, так и об особенностях фазового состава и структуры доэвтектоидной стали (в частности о состоянии перлита в доэвтектоидной стали). Подытожим основные наблюдения и выводы работы, иллюстрирующие это.

На температурной зависимости намагниченности в достаточно большом постоянном внешнем поле $(H=10 \mathrm{kOe})$ наблюдаются особенности, связанные, как с необратимыми превращениями (в окрестности температуры эвтектоидного превращения стали $T_{e} \approx 1000 \mathrm{~K}$ ), так и с обратимым превращением ферромагнетик-парамагнетик при $T_{\mathrm{C}}(\approx 1043 \mathrm{~K})$.

Описание кривых намагничивания доэвтектоидной стали в области приближения к магнитному насыщению успешно осуществляется с помощью закона Акулова с учетом слагаемого, связанного с парапроцессом, характеризующимся магнитной восприимчивостью $\chi$. Последнее слагаемое вносит большой вклад в намагниченность вблизи температуры Кюри, а магнитная восприимчивость демонстрирует пик при $T_{\mathrm{C}}(\approx 1043 \mathrm{~K})$. В окрестности $200 \div 250 \mathrm{~K}$ наблюдается еще один пик на зависимости $\chi(T)$. На основе анализа приближения намагниченности к насыщению мы связываем этот пик (вблизи $T_{\mathrm{C}}^{*} \sim 240 \mathrm{~K}$ ) с температурой Кюри замещенного цементита $(\mathrm{Fe}, \mathrm{Mn})_{3} \mathrm{C}$, формирующегося в структуре перлита доэвтектоидной стали. Показано, что температурный ход намагниченности насыщения стали успешно описывается универсальным уравнением, предложенным в работе [18]. Магнитостатическая неоднородность, связанная с пластинчатой структурой перлита, дает основной вклад в величину энергии локальной магнитной анизотропии, что приводит к более медленному, в сравнении с чистым железом, приближению намагниченности к техническому насыщению. В окрестности температуры Кюри цементита наблюдается скачкообразное изменение энергии локальной магнитной анизотропии, связанное с резким изменением обменного и диполь-дипольного взаимодействий между пластинами железа и цементита в структуре перлита. Наблюдение смены степенных закономерностей в приближении намагниченности к насыщению указывает на формирование двумерных нанонеоднородностей локальной оси легкого намагничивания в пластинах альфа-железа входящих в состав перлита.

В заключение отметим, что выводы, касающиеся структуры и фазового состава сделанные на основе магнитоструктуных исследований в дальнейшем должны верифицироваться с помощью прямых методов исследования структуры и фазового состава.

\section{Финансирование работы}

Исследование выполнено при финансовой поддержке Российского фонда фундаментальных исследований, Правительства Красноярского края, Красноярского краевого фонда науки в рамках научного проекта № 20-48-242905 р_Енисейская Сибирь „Определение 
влияния намагниченности ферромагнетиков на МГДпараметры работы электролизера“.

Магнитные измерения были проведены с использованием оборудования Центра коллективного пользования ФИЦ КНЦ СО РАН.

\section{Конфликт интересов}

Авторы заявляют, что у них нет конфликта интересов.

\section{Список литературы}

[1] W. Pepperhoff, M. Acet. Constitution and Magnetism of Iron and its Alloys. Springer Berlin Heidelberg, Berlin, Heidelberg (2001). 213 p.

[2] H. Bhadeshia, R. Honeycombe. Iron-Carbon Equilibrium and Plain Carbon Steels. In: Steels Microstruct. Prop. Elsevier (2017). P. 59-100.

[3] Y. Li, D. Raabe, M. Herbig, P.-P. Choi, S. Goto, A. Kostka, H. Yarita, C. Borchers, R. Kirchheim. Phys. Rev. Lett. 113, 106104 (2014)

[4] M. Reibold, P. Paufler, A.A. Levin, W. Kochmann, N. Pätzke, D.C. Meyer. Nature 444, 286 (2006).

[5] Б.А. Апаев. Фазовый магнитный анализ сплавов. Металлургия, М. (1976). 283 с.

[6] Л.А. Чеканова, Е.А. Денисова, О.А. Гончарова, С.В. Комогорцев, Р.С. Исхаков. ФММ 114, 136 (2013).

[7] С.Н. Варнаков, J. Bartolome, J. Sesé, С.Г. Овчинников, С.В. Комогорцев, А.С. Паршин, Г.В. Бондаренко. ФТТ 49, 1401 (2007).

[8] M. Dupuis, V. Bojarevics, J. Freibergs. Light Metals TMS (The Minerals, Metals \& Materials Society). 453 (2004).

[9] V. Bojarevics, E. Radionov, Y. Tretiyakov. Light Metals / Ed. O. Martin. The Minerals, Metals \& Materials Series. 551-556 (2018). DOI: 10.1007/978-3-319-72284-9_72

[10] Сталь углеродистая обыкновенного качества (ГОСТ 3802005), РФ(2008)

[11] S. Chikazumi. Physics of Ferromagnetism. 2nd ed. (2009). $672 \mathrm{p}$.

[12] S.W.J. Smith, W. White, S.G. Barker. Proc. Phys. Soc. London. 24, 62 (1911).

[13] N.S. Akulov. Zeitschrift Phys. 69, 822 (1931).

[14] В.А. Игнатченко, Р.С. Исхаков, Г.В. Попов. ЖЭТФ 82 , 1518-1531 (1982).

[15] R.S. Iskhakov, S.V. Komogortsev. Phys. Met. Metallogr. 112, 666 (2011).

[16] К.П. Белов. УФН 65, 207 (1958).

[17] С.В. Вонсовский. Магнетизм. Наука. М. (1971). 1032 с.

[18] M.D. Kuz'min. Phys. Rev. Lett. 94, 107204 (2005).

[19] B.P. Khrustalev, A.D. Balaev, V.G. Pozdnyakov. Thin Solid Films 130, 195 (1985).

[20] Р.С. Исхаков, С.В. Комогорцев, А.Д. Балаев, А.В. Окотруб, А.Г. Кудашов, В.Л. Кузнецов, Ю.В. Бутенко. Письма в ЖЭТФ 78, 271 (2003).

[21] Н.Б. Мельников, Б.И. Резер. ТМФ 181, 358 (2014).

[22] D.A. Balaev, S.V. Semenov, S.N. Varnakov, E.Y. Radionov, Y.A. Tretyakov. J. Sib. Fed. Univ. Math. Phys. 14, 5 (2021).

[23] U.Köbler. J. Magn. Magn. Mater. 491, 165632 (2019).

[24] H.K.D.H. Bhadeshia. Int. Mater. Rev. 65, 1 (2020).

[25] Л.В. Киренский, В.П. Рябинин. Кристаллография 7, 644 (1962).
[26] Н.С. Акулов, Л.В. Киренский. ЖТФ 9, 1145 (1939).

[27] Л.В. Киренский, Л.И. Слободской. Докл. АН СССР 70, 809-811 (1950).

[28] H. Kronmuüller, A. Seeger. J. Phys. Chem. Solids 18, 93 (1961).

[29] В.В. Парфенов, Ю.П. Лобастов. ФММ 16, 334 (1963).

[30] M. Fähnle, H. Kronmüller. J. Magn. Magn. Mater. 8, 149 (1978).

[31] S. Yamamoto, T. Terai, T. Fukuda, K. Sato, T. Kakeshita, S. Horii, M. Ito, M. Yonemura. J. Magn. Magn. Mater. 451, 1 (2018).

[32] С.В. Комогорцев, Р.С. Исхаков, А.Д. Балаев, А.Г. Кудашов, А.В. Окотруб, С.И. Смирнов. ФТТ 49, 700 (2007).

[33] C. Zener. Phys. Rev. 96, 1335 (1954).

[34] J. Briki, S. Ben Slima. J. Met. 2012, 1 (2012).

[35] V.T. Witusiewicz, F. Sommer, E.J. Mittemeijer. Met. Mater. Trans. B 34, 209 (2003).

[36] G.P. Huffman, P.R. Errington, R.M. Fisher. Phys. Status Solidi 22, 473 (1967).

[37] А.И. Ульянов, А.А. Чулкина, В.А. Волков, Е.П. Елсуков, А.В. Загайнов, А.В. Протасов, И.А. Зыкина. ФММ 113, 1201 (2012).

[38] Б.Н. Арзамасов, И.И. Сидорин, Г.Ф. Косолапов. Материаловедение. Машиностроение, М. (1986). 384 с.

[39] D.A. Balaev, I.S. Poperechny, A.A. Krasikov, K.A. Shaikhutdinov, A.A. Dubrovskiy, S.I. Popkov, A.D. Balaev, S.S. Yakushkin, G.A. Bukhtiyarova, O.N. Martyanov, Y.L. Raikher. J. Appl. Phys. 117, 063908 (2015).

[40] D.A. Balaev, I.S. Poperechny, A.A. Krasikov, S.V. Semenov, S.I. Popkov, Y.V. Knyazev, V.L. Kirillov, S.S. Yakushkin, O.N. Martyanov, Y.L. Raikher. J. Phys. D 54, 275003 (2021).

[41] H. Hoffmann. J. Appl. Phys. 35, 1790 (1964).

[42] K.J. Harte. J. Appl. Phys. 39, 1503 (1968).

[43] Р.С. Исхаков, В.А. Игнатченко, С.В. Комогорцев, А.Д. Балаев. Письма в ЖЭТФ 78, 1142 (2003).

[44] В.А. Игнатченко. ЖЭТФ 54, 303 (1968).

[45] В.А. Игнатченко, Р.С. Исхаков. ФММ 6, 75 (1992).

[46] R.S. Iskhakov, S.V. Komogortsev, A.D. Balaev, A.A. Gavriliuk. J. Magn. Magn. Mater. 374, 423 (2015).

Редактор Д.В. Жуманов 